of different ages kept under farm conditions indoor and at pasture. Observations were often made continuously for several hours and occasionally for periods of up to twenty-four hours. During the past two years or so, the same individual animals have been observed over an extended period. In addition to these purely observational methods, various experimental procedures were also adopted and the play reactions studied.

Play does not occur uniformly throughout the life of cattle : the following are the conditions under which it has been observed.

(A) General. Play occurs in the young more than in the adult; in the well-fed healthy animal-poorly fed or sick animals play less, if at all ; during good weather conditions-cold, wet weather definitely does inhibit play ; in animals kept continuously at pasture without any unusual event occurring play is most likely to occur in later afternoon, and not much, if at all, during midday hours. Play, however, has been observed around midday in cattle at pasture when they saw other cattle being led down an adjoining track.

(B) Particular. Play will often occur on being released after a long period of confinement, when vigorous play is seen even in adult cattle; during a period soon after feeding-this is often seen in young calves which are being bucket-fed with milk twice daily, and, though not so frequently, in cattle out of doors following the afternoon feeding period. If an observer, after scratching itchy areas of the skin, moves off at a quick walking pace, the animal may follow, playfully kicking up its heels; in animals gaining access to new terrain, when they play immediately, or the instincts of hunger or curiosity may have precedence, in which case play may occur after these instincts have been satisfied.

Brownlee suggests that play in cattle, instead of being, as Groos thought, manifestations of a number of instincts before they are actually required for serious purposes, is one instinct with its own drive, releasers, emotion, consummatory phase and goal.

The goal of play is not to be found in the animal's environment but is tissue-trophic and serves to exercise and thereby maintain tone and adequate vascularization of the play muscles and the other structures involved in play behaviour.

A derived survival value of play is the familiarizing to the animal of certain items in its environment in relation to its play movements : play continues in an environment long after this familiarity has been established.

There is variation in the type of releaser to which individual cattle respond. Sex and age modify the manifestations of play. Rivalry, if it operates at all in play in cattle, is only a minor motive.

It may be that the tendency during play for the behaviour pattern to switch in succession from one type to another can be interpreted as being due to diffusion of stimuli from one centre to another within the central nervous system; that the releaser of play is a gestalt and all the play items in that gestalt become valent together is also possible.

The tendency for a bovine animal to play is influenced by its state of nutrition.

The term 'para-activity' is suggested for play to indicate that, although play resembles in its behaviour the patterns of combat, self-defence, flight and sex mounting, it is, in fact, an entirely distinct phenomenon.

\section{PROTEIN METABOLISM IN LEAVES}

TN a recent paper, A. C. Chibnall has described some experimental work relating to the protein meta. bolism in rooted runner-bean leaves (New Phytol., 53, $1,31 ; 1954)$. The observations of many workers have shown that the detachment of a leaf from the parent plant is followed by a rapid breakdown of protein in the lamina, the rate of this process varying from species to species, from leaf to leaf with age for the same species, and also with the carbohydrate level. If detachment of the leaf from the plant leads to some interference with the mechanism of protein synthesis, it seemed possible that some influence of the root-system, for example the upward translocation of a hormone, is responsible for the regulation of the protein-level in leaves. In the investigation now reported it has been shown that the development of roots on the petiole of a detached leaf of runner bean, induced by treatment with indoleacetic acid, arrests the rapid breakdown of protein in the lamina; and that under suitable conditions this isolated leaf can be kept alive and healthy for several weeks. By contrast, leaves with their petioles in water showed the characteristic rapid breakdown of protein, accompanied by the movement of non-protein nitrogen into the petiole, and chloroplast degeneration took place in a few days. The author's summary of the evidence is as follows. "It would appear that on detachment of the leaf from the parent there is initiated almost at once a strong directional shift of nitrogen (and almost certainly of carbohydrate) from the blades towards the distal end of the petiole. This is presumably the normal response of a plant organ to wounding, just as it is known to be in animal organs. If conditions do not favour the healing of the wound and the initiation of root growth, the drain of nitrogen from the blades, accompanied by breakdown of protein, carries on at a high rate and toxic symptoms become apparent within a few days, irrespective of the carbohydrate supply. On the other hand, should conditions, brought about, for example, by treatment with hormones, favour rooting, the rate of outflow of nitrogen to the petiole and also the rate of protein breakdown in the blade is much retarded, and the onset of toxic symptoms may be delayed many days if not weeks. The development of adventitious roots on the petiole of a detached leaf therefore does indeed influence the rate of protein breakdown in the blade.

"This observation provides us with an answer to one of the queries underlying the present investigation. But in itself it provides no direct evidence bearing on the larger question of whether a protein cycle is operative in these detached, and hence by inference in the normal, leaf blades. A cycle implies continuous synthesis as well as breakdown, and it was to obtain evidence that protein synthesis might be going on concomitantly with the observed rapid protein breakdown in the detached leaves that the studies recorded in the following paper were carried out."

In a further study, again using detached runnerbean leaves, A. C. Chibnall and G. H. Wiltshire (ibid., 38) have investigated the protein metabolism, using isotopic nitrogen. Detached leaves of the runner bean were kept for four days in the dark with the petiole immersed in a solution of ammonium 
chloride containing isotopic nitrogen. As was expected, considerable protein breakdown occurred in the blades during this period. The residual protein of the blades was extracted, and on analysis was found to contain isotopic nitrogen. The lysine isolated from the hydrolysis products of the residual blade protein was found to contain isotopic nitrogen in both its amino groups. The results are considered to provide evidence for the occurrence of a proteincycle in leaves, protein synthesis being maintained in spite of conditions which enhance the rate of protein decomposition.

\section{GROWTH-PROMOTING SUBSTANCES IN THE OVARY AND IMMATURE FRUIT OF THE BANANA}

BY PROF. F. C. STEWARD

Department of Botany, Cornell University, Ithaca, New York

AND

\section{DR. N. W. SIMMONDS}

Banana Research Scheme, Imperial College of Tropical Agriculture, Trinidad

$\mathrm{T}$

HE observations to be described stem from the idea that vegetatively parthenocarpic development of the edible banana fruit results from the autonomous liberation of growth-promoting substances in the ovary: substances which, in the seeded fruit, would only be liberated after, and as a consequence of, fertilization'. The starchy parenchyma that fills the edible banana and surrounds the seeds in seeded kinds originates from the inner layer of the pericarp (the 'lining') ; this is the formative layer that responds to growth-promoting substances, though it does not necessarily produce them.

In other work it has been shown that the liquid endosperm of the coconut, that is, the fluid that nourishes an immature embryo, has a great ability to promote cell divisions in mature cells that otherwise would not grow. This has been observed in the case of carrot root phloem, cut far enough from the cambium so that growth by cell division had subsided $^{2}$. In a basal medium (containing a complete range of the organic and inorganic nutrients normally furnished to plant tissue cultures and the vitamins commonly added as supplements), tissue explants of the phloem of carrot root do not grow appreciably. If whole coconut milk is added, they grow rapidly ${ }^{3}$, and this effect is not due primarily to indoleacetic acid or related compounds ${ }^{2}$. Some other dicotyledonous tissues respond in a similar way (artichoke tuber ${ }^{4}$ ), whereas others require other stimulants in addition to coconut milk (for example, 2,4-dichlorophenoxyacetic acid for the potato tuber ${ }^{5}$ ). By the use of coconut milk, randomly proliferating tissue cultures of a monocotyledon have been obtained for the first time $\theta^{6}$. Nor is coconut milk a unique source of this activity, for it (or its equivalent) has been found to occur, and has been assayed by means of the carrot tissue culture system, in other monocotyledonous sources as well as in a dicotyledon?
In all these cases, however, the source of the growthpromoting activity has been the nutrient medium of an immature embryo, and the substance, or substances, responsible accumulate in a situation in which the storage tissue develops precociously with respect to the embryo?

The carrot tissue culture system, growing in liquid media under the controlled conditions which have been devised for the purpose ${ }^{8}$, therefore constitutes a convenient assay system for suspected growthpromoting materials which can produce an effect equivalent to that of coconut milk, that is, active cell division in cells in which this would otherwise not occur. The purpose of the tests here described was to ascertain whether such activity could be demonstrated in extracts of banana ovaries and thus furnish a clue to the causal factors in the development of these fruits.

Methods. Aqueous and alcoholic extracts of the 'linings' of ovaries (see above) ${ }^{\mathbf{1}}$ of 'pisang lilan' (an edible form of Musa acuminata) were made at 'receptivity' and after four weeks. Materials for test were obtained from the collections of the Banana Research Scheme, Imperial College of Tropical Agriculture, Trinidad. In the receptive ovaries the linings were very thin and a bunch yielded only $a$ sample of $6.4 \mathrm{gm}$., which was divided between the two types of extract. At four weeks, $5 \mathrm{gm}$. of material were dissected out and used in each type of extraction. Extracts were made by two different methods: (a) by pounding the tissue in cold water, filtering, and then concentrating the solution in vacuo at room temperatures; (b) by extracting the tissue with hot alcohol and concentrating the extract on a waterbath. These extracts were sealed in tubes with a preservative (chloroform or toluene) and dispatched from Trinidad to Ithaca, New York, for test. (The carrot assays were performed under arrangements made possible by grant $C-1357\left(C_{2}\right)$ from the National Cancer Institute, National Institutes of Health of the United States Public Health Service, and with the assistance of Mrs. Alice Peabody and Mr. E. M. Shantz.) On arrival, the materials were evaporated to dryness, the preservatives were removed, and the residue re-dissolved in warm distilled water. The solution, made to $30 \mathrm{ml}$. volume, was used in the carrot assay test by adding it in place of coconut milk to : (a) basal medium; (b) basal medium supplemented by casein hydrolysate $(0.05$ per cent). The carrot explants used were drawn from a stock which responded appreciably to casein hydrolysate (initial weight $2.6 \mathrm{mgm}$.; final weight in basal medium $6.1 \mathrm{mgm}$.; in basal medium plus casein hydrolysate $16 \cdot 1 \mathrm{mgm}$.$) .$

Results. Results obtained after fifteen days of growth are summarized in Table 1 ; they may be interpreted as follows : (a) The population of carrot explants used requires coconut milk to grow and, independently of this response, growth may be increased by casein hydrolysate. (b) The extract of banana ovaries acts as a source of that part of the growth-promoting effect of coconut milk which requires, but is not replaceable by, casein hydrolysate. (c) There is some indication, from comparison of the two times of extraction, that the growthpromoting activity declines with time and with the development of the fruit. Extraction of the growthpromoting factor by alcohol is more efficient than extraction by water.

In short, the response to the banana extract corresponds to that more specific moiety of the coconut 